\title{
Some Interesting Artistic Games in Teaching Arts for Elementary Level Schoolchildren
}

\author{
Islomov Eldor
}

\begin{abstract}
Artistic games, especially, toy is a specially designed for children's enthusiasm and raising interests. It can help children to develop their talents, to become interested in what is reflected in them, and to develop their independence. Games with plasticin and clay give children a sense of friendship and the ability to coordinate their actions. This is the main topic what this article deals with.
\end{abstract}

Keywords : Clay, plastic, pre-school education, visual activity, creativity, aesthetic taste.

\section{INTRODUCTION}

Making toys with some pieces of plasticilin and clay is very important in the education and upbringing of preschool children. It helps you to understand the features needed for successful schooling, to develop memory, image thinking, and to develop the skills and skills you need. Tattoo making, like any other kind of visual activity, shapes aesthetic taste, teaches you to sense beauty and to understand its diversity.

Adults need to learn and understand the age characteristics of children and, accordingly, create and select toys and teach children how to make them.

\section{LITERATURE REVIEW}

Artists and scholars engaged in the sphere of pedagogics and art as Azimov B., Apuxtin O.K. ,Mirjalilova S. , Aripov B.O. tried to find out new methods in the lessons of Fine Art and suggested factors for improving efficiency of teaching arts in pre-school organizations and schools.

The perception of a young child is particularly acute. The memories of childhood can be remembered forever. Perceptions of beautiful things help children to develop aesthetic sense, respect and care about art. The artwork extends the child's knowledge as he provides specific information. Such works can be used to create moral feelings in children.

\section{DISCUSSION}

If Making clay and plastic toys in school, the visual activity involves reflecting the realities of children's activities and creating elemental toys using clay or plastic. Even making a child's simplest toy is a creative process. For

Revised Manuscript Received on October 15, 2019.

* Correspondence Author

Islomov Eldor*, A teacher of Bukhara State University (Uzbekistan), Arslonov Qahramon Polvonovich, A docent of Bukhara State University.

example, a small piece of clay looks like a ball, orange, apple, and a clay pillar round the ends, joining a ring and a hole. At work, the child enjoys the softness, the volume of the clay, and the joy of the shape he or she makes.

The child understands various properties of clay and plastic, learns about the shape, structure and proportions of the subject, and learns how to direct the target with a precise movement of hands, to develop constructive abilities. If this activity is handled properly, making clay and plastic toys can become a favorite activity of children. In the course of making clay and plastic toys, educators are tasked with: developing children's creativity, developing visual and technical skills, and engaging in this type of activity. The school education system is designed to prepare children for school.

The rapid development of children's visualization techniques allows them to make two or three figure sketches that are earlier than applause or drawing. For example, the picture is depicted at the bottom of the large-scale subject page and larger. The figures made of clay or plastic are placed on a board or clay plate in real space.

All activities form an independent approach to the child's search for new ways of visual representation. When making clay and plastic toys, children will be better able to look for something new to teach them what they need. This can help correct the mistakes by straightening the shapes with your fingers, wooden pencils, plastering mud, or removing excessive sludge that prevents the shape. The child can then re-shape the form several times. This is not the case with a picture or an application.

Different types of visual activity shape a child's artistic taste. If drawing and application influence the aesthetic education of children through the clarity and color of the lines, the size, softness and rhythm of the subject matter in making the toys. All of these three components are present in real space, giving the child the ability to quickly perceive and perceive the plastic shape of the objects, the proportions of the parts, and develop attention and interest in the surrounding realities.

Making clay and plastic toys as a type of activity teaches children to use space and learn mathematical concepts more quickly than drawing or applying.

For example, in a small group, children make stacks for barriers, the child picks them up, sets them in rows, builds a wall around the house, calculates how many columns they have made, and so on. 
Adult school children think about where to attach their members to a human figure. Here they compare and compare parts of a figure directly with each other and with the whole figure, and determine their size, size (length, thickness). Whereas, in the drawing, this can only be done with the eyes.

Making clay and plastic toys also play a role in aesthetic education, such as painting.

\section{ANALYSIS AND RESULTS}

Research and case studies in schools show that, as a result of the education given to children, they can create expressive images from school age. Because when making different toys of clay and plastic, they act like sculptors and use many visual aids and techniques (enlarge the volume, movement, content with the details), but each of these works in their own way. will do. It depends on the level of knowledge and skills of each child. For example, the form of their work is simplified: children make a human head with a round ball and legs and arms in the form of a cylinder. As the child begins to describe the details, he or she will continue to use them, almost without any distinction, depending on their level of expression. Sometimes the main part of the figure remains, and he begins to make secondary pieces. The content of children's toys is also unique. If the content of the sculpture is mainly about making living things, children will try to create almost anything in their surroundings. The reason for this is that for children of school it is often difficult to understand the meaning of plastic in the subject, and they still do not feel the beauty of the plastic forms. When they make something from clay or plastic, they often think that one purpose is to create something and then play it.

Preschoolers use wooden pencils under the tutorial and guidance of the tutor, select the carcasses, and use them not only to attach the parts, but also to represent the characteristics of the shape.

Children work with three types of clay and plastic: subject, plot and decorative toys. Each of them has its own features and functions, and can be made both on the task and on the topics that children find.

Designing certain subject toys makes it easier for a child, for example, to draw a picture, because the toy maker works with real size and does not use conditional expressions. Children make their human and animal figures interesting.

They also learn to express constructive objects faster than plastic. Studies show that children can be taught how to properly represent human and animal images in a constructive and plastic way.

The school is therefore supposed to teach children the basic form of the subject and the most obvious characteristic.

Making plot toys also has its own peculiarities of drawing compared to drawing. In the picture, the plot is often associated with the use of conditional imaging techniques (for example, if a person's side image is represented by a single view; the first-order objects are described as larger than the second-figure items, etc.). The making of yachts does not require the conventional modification of shapes and the reduction of proportions in order to create space vision.
Children generally do not seek to portray a broad plot - this can be seen in small and medium groups in the garden and sometimes in large groups. The boy may be restrained, for example, by the girl and the chick, but she starts playing them right away. Moving the shapes on the table, saying something appropriate for the action fills the child's toy with dynamics, an imaginary episode become participants. Usually making plot toys starts with this game. Children are interested in this type of toy, and because they learn how to draw, they make a wide range of toys.

Each type of visual activity allows children to develop mental activity, creativity, artistic taste and other qualities. Without these qualities, the basics of a socially active person cannot be formed. The development of these qualities in clay and plastic toys makes them unique. For example, the size of any object and the child perceives it from every angle. Based on perception of the subject, the image of the school is formed. He draws on his knowledge of the realities of making toys, which reflects not all aspects of a child's subject matter, such as painting or making applications.

Because he no longer has to use conditional expression, which is necessary in other types of visual activity. In addition, making clay and plastic toys makes drawing and drawing more natural than with applications. The active movement of the hands leads to a clearer shape. As a result, children are more likely to master the techniques of imaging and are able to work independently without adult instruction, which in turn contributes to the rapid development of children's creativity.

Another feature of making clay and plastic toys is its inextricable connection to various games. The size of the completed figure encourages children to play different games using this toy. The little ones start their games immediately after the training and start various games. This child-friendly feature enables you to play a wide range of topics related to the game. For example, children can make clay and plastic dishes and small figures for their dolls, spacecraft, zoo, hockey and other games. Playing the game in a fun way will increase the children's interest in making clay and plastic toys, and will increase the chances of engaging with adults and peers.

Making clay and plastic toys sometimes requires a specific approach to training. For example, depending on the size of the case, one topic can be explained in one or two sessions, not in one. Making something from clay and plastic and plastering it takes longer - 30 to 35 minutes. To display a fabricated toy, it is necessary to create a circle with a rotating circle. This diaper allows you to watch the subject from all angles.

Considering the fact that making a clay or a plastic picture is easier for a child than drawing a painting, it is best to start with plastic shapes. You can then switch to drawing on a piece of paper with a pencil or paint. 
Creating a plot toy requires the child to work hard, because he or she needs to make every item in the composition, install it in a diaper or without a foundation and fill it with details.

To create a compositional composition, you first need to think about the base, its size and shape, and then create, distribute and consolidate the material. Often children do not initially consider the size and shape of the diaper, do not reinforce it, and make it thin. The shape and size of the diaper are not consistent with the general ice, the shape and size of the figures. The reason for this is that children of this age have a diaper only on the surface (floor, floor), with objects placed on it. The educator should teach the children how to make a thick, sufficiently sized and beautiful base, and to place the items in a logical manner. This will allow successfully solving the tasks of composite character.

There are episodes of life around, some of the fairy tales and stories and can be a plot for plastic toys. The expressiveness of the plot compositions depends not only on how much the children can describe the shape, but also on the way the characters interact with the images. The main task of making plot toys is to help children think and describe the composition of 2-3 subjects; creative approach to the decision-making and articulation of the main thing; their knowledge of the shape and proportions of the objects, their observations on the movement of living objects, and the use of various techniques for making toys.

Made of plaster and plastic toys, only the large and ready-made groups of the garden. Because a child needs to know a lot about the subject and be able to use different ways of describing it. In previous groups, children are only prepared to make plot toys and acquire the necessary knowledge and skills. Making Decorative Toys One of the ways in which children can be taught aesthetically is to introduce children to applied art, its various types, including fine decorative plastic of folk masters. The beautiful generalized forms of dolls, animals, birds make children happy and have a positive effect on their artistic taste, broaden their imagination and imagination. Beautiful pottery made by potters of different nations is a pleasure for children. Children enjoy simple, sometimes weird cakes, salts and wreaths.

Large groups of children can look at miniature decorative plastics by folk artists, decorate the room, and make fun gifts. They decorate dolls and jewelry for fun and make decorative dishes: salts, egg diapers and small vases for spring flowers, cups and pens. These items are in the form of leaves, flowers, animals and can be decorated with guash or guash. Beautiful decorative birds with wings and tail also should be included in this type of toy design. Decorative toys make it possible for children to learn how to think first, to make sketches in pictures, and to decide contingent shapes and patterns. For example, winged bird or beetle wings, in the form of salt flowers, represent various decorative elements: geometric shapes (circles, squares, rhombs, triangles, etc.), plant forms (wet fruits, leaves, grass, flowers and etc).

It is useful for children to recommend decorative plates and other wall decorations with ornaments. Using a decorative plate, children learn how to use tools, how to make

toys, and most importantly, to fill the space with beautiful decor. Some elements can be made with a special pencil, such as tube, square, triangle and other shapes. Screws and screws of various shapes can be used as tools. On a clay plate, draw a wooden pencil. This will be done by drawing on a plate and then drawing ornaments on it. They are slightly removed from the overall surface of the plate. This activity affects the development of small muscles in the fingers, the child's fingers; teaches you to work with the tips, to make your fingers flex and feel better.

Clay and plastic are often used for toys in schools.

Clay should be the main material in teaching the child to make toys. Because it is a plastic, uniform, beautiful material that enables the child to understand the integrity of the shape of the objects. The child can make a lot of toys and several toys from one clay pot that cannot be done with plastic. Clay has another advantage over plasticity; clay pots can be further processed in the muffin oven or added to the egg yolks after drying.

The use of plastic in making toys usually results in small shapes with colored parts. This is not always appropriate, and it prevents the overall perception of the form. Because the educator will not be able to give the child a large plasticin of color just enough to make an interesting set of toys. In addition, it is a color material and color as an additional visual tool often distracts the child from painting the main thing - the shape. All of this complicates the important function of the preschool program - teaching children to view and create basic forms of subjects.

It should be noted that for 2-4 year olds, this material is slightly warmed before the workout, but it is difficult to handle. The use of Plasticin in working with 57-year-olds is good because they have small muscles in their hands that are well developed to express small details of the subject: the desire to decorate the shapes of clothes, the plants in plot games. However, even in large groups, plasticin should be used only for certain classes. Thus, clay is the main material in the work with children. So, where to get the sludge for fun?

The mud can be obtained directly from the ground. Sandy is found in soil, muddy clay, readily available near rivers and ditches. Therefore, the sludge should be searched during the summer when the school is moved to the backyard.

Many educators find it difficult to find clay. They are afraid of making clay. In fact, it's not that difficult. Once a good clay is molded, it can be used all year round.

If it is dry, grind the pieces and sticks with a hammer, put them in a bowl and pour water over it to keep the soil dry.

Liquid sludge is put on a hot surface to solidify. Such soil clearing is a long process. So it's best to do it during the summer.

Sculptors' pencils should be used when making clay toys. Such cuttings may be made of wood or metal. Wooden cuttings can be made by hand. The simplest cuts are the sharp and sharp edges of one end and the other with rounded, rounded, and slender grass. 
Hand-cut pencils are used to handle difficult parts of the hand; With the help of them, excessive sludge in the form is removed and traces are removed. The quality of a child's work depends on how he or she arrives. You will need smaller (square or circle) boards for this. They are placed on the table. The size of the board depends on the size of the toy to be made. If the toy size is $10-15 \mathrm{~cm}$, the size of the board is $22 \times 35 \mathrm{~cm}$. The bigger the toy is, the bigger the board is.

\section{CONCLUSION}

Even toys made by children and not cooked in muffler ovens are dirty in the same order unless they are needed. After the soil has been absorbed thoroughly (a day or two later), it is mixed with wood, then poured some water and made by hand, and made of clay (in the preparation group the children themselves can do this). . The prepared sludge is put into a plastic container. If there is no such container, a piece of clay is wrapped in polyethylene film and sealed tightly to prevent air passage and put into a container, barrel, bucket or similar container. In this case, the sludge can be stored year-round. It is periodically inspected and sprinkled with water.

Dirt, rocks, or metal particles may be involved in the soil. At the same time, it is "cleansed." This work is done as follows. The soil is crushed with a hammer. Put it in a bowl and pour water over it until the mass is soaked. The mass is then transferred to another container. The garbage in the sieve is discarded.

\section{REFERENCES}

1. Apuxtin O.K. Lessons in Fine Art and Factors for Improving Efficiency, "T., 1990.

2. Mirjalilova S. and b. "Bolajon" base program.-T., 2010. - 214b.

3. Aripov B.O. "Lessons of Fine Art and Factors for Improving Efficiency" Tashkent 1997

4. F. Kodirhodjaev Fine arts and crafts in school - T., The teacher, 1991.

5. Sakulina NP, Kamarova T.S. Illustrated activities in school. -T., "Teacher", 1996.

6. Safa Open. Spirituality and upbringing of independence. -T . "Uzbekistan", 1995.

7. Sodirov N. Treasury of cultural monuments. -T .: "Science", 1981.

8. Umarov E. and others. Fundamentals of Aesthetics. - T $\therefore$ Cholpon Publishing House, 2009. 208 p.

9. Vetlugina N.A. Aesthetic education in school. -T., "Teacher", 1997.

10. Khalezova N.B. and b. Making of clay and plastic toys in school. -T : Teacher, 1991. 192b.

11. Hasanov R. Aesthetic education in subject-based drawing. -T., "Teacher", 1990.

12. Hayitmetov A. Horizons of our literary heritage. -T .: "Teacher", 1997.

13. Yusupov E. Spiritual basis of human development. -T .: "University", 1998.

14. Professional Development Institutions: http://www.pedagog.uz 